\title{
SHAME, EMBARRASSMENT, AND THE SUBJECTIVITY REQUIREMENT
}

\author{
Erick J. Ramirez \\ Santa Clara University \\ Original scientific article - Received: 01/02/2018 Accepted: 18/07/2018
}

\begin{abstract}
Reactive theories of responsibility see moral accountability as grounded on the capacity for feeling reactive-attitudes. I respond to a recent argument gaining ground in this tradition that excludes psychopaths from accountability. The argument relies on what Paul Russell has called the 'subjectivity requirement'. On this view, the capacity to feel and direct reactive-attitudes at oneself is a necessary condition for responsibility. I argue that even if moral attitudes like guilt are impossible for psychopaths to deploy, that psychopaths, especially the "successful" and "secondary" subtypes of psychopathy, can satisfy the subjectivity requirement with regard to shame. I appeal to evidence that embarrassment and shame are grounded on the same affective process and data that psychopathic judgments about embarrassment are neurotypical. If I am right, then psychopaths ought to be open to shame-based forms of accountability including shame punishments. I conclude by considering why psychopaths rarely selfreport shame. I argue that lacking a capacity to see oneself as flawed is a different sort of failure than lacking the capacity to feel.
\end{abstract}

Keywords: accountability, embarrassment, psychopathy, reactive attitude, shame

\section{Introduction}

In this paper, I focus on a criticism of psychopathic accountability grounded in what have historically been referred to as reactive theories of responsibility. Although I will not offer a general defense of the framework here, reactive theories of responsibility have enjoyed resurgence of late (Russell 2004; Talbert 2012; Wallace 1994). In part, this resurgence owes its origin to the methodological assumptions built into reactive theories of responsibility.

Traditional theories of responsibility typically take metaphysical questions as a starting point. These approaches begin by examining the concepts of responsibility, freedom, and determinism and then use the theory that emerges to make sense of, and critique, our everyday practices involving responsibility. Of central focus in these accounts are questions stemming from the compatibility of responsibility with physical determinism. Reactive theories of responsibility invert this relationship by favoring an examination of a community's practices over metaphysical issues. Reactive theorists claim that we can learn what responsibility amounts to by studying the behaviors that ground the family of practices involved in holding someone responsible (Strawson 1962). In doing so, reactive approaches avoid traditional pitfalls associated with philosophical questions over the nature of free will and determinism. For the reactive theorist, the existence of a 
set of responsibility-ascribing practices is evidence of the irrelevance of metaphysical issues to questions of responsibility. Whether or not physical determinism is true, they argue, our practices of praising and blaming would survive (Strawson 1962).

An additional claim that is shared by reactive theories of responsibility, and one I examine closely in this article, is that to be the type of being that can be held responsible at all, an agent must have the capacity to feel reactive-attitudes and direct them at oneself. Following Paul Russell, I will call this demand "the subjectivity requirement" (Russell 2004). Reactive theories of responsibility are reactive in the sense that the ultimate basis for our responsibility-ascribing practices (praise, blame, formal and informal punishments, etc.) is located in the conditions that make it appropriate for individuals to direct reactive-attitudes at themselves and others. Responsibility ascriptions are grounded on affective expressions (i.e., reactive attitudes) of distinct types. Reactive-attitudes include any emotions that we feel toward others (and ourselves) as a response to perceived intentional behavior.

Contrary to other theories of responsibility that require agents to verbally articulate or defend the reasons behind their actions (Smith 2012), reactive theorists hold that it is an agent's capacity for reactive-attitudes that ground our practices of praise and blame. Paul Russell and other reactive theorists have argued that psychopaths are incapable of satisfying this subjectivity requirement (Fischer and Ravizza 1998; Greenspan 2003; Russell 2004); they therefore conclude that psychopaths cannot be held accountable or that this fact diminishes the degree to which they are responsible. ${ }^{1}$ Although the subjectivity requirement has intuitive force, especially when it comes to explaining why it would be unfair to hold someone responsible on the basis of emotions they cannot understand, I challenge the claim that psychopaths fail the subjectivity requirement especially with regard to reactive-attitudes like shame.

I focus my attention on a promising account of shame, however, my arguments are compatible with a wide range of theories of the nature of shame and embarrassment. On my view, shame and embarrassment are not differentiated by unique physiological or neurological profiles. Very few emotions can be differentiated in this way (Lindquist et al. 2012; Ramirez 2017a; Russell and Barrett 1999). Instead, shame and embarrassment are differentiated behaviorally according to what the persons who are experiencing the emotion express to others about their situation when they use labels like 'shame' or 'embarrassment' to describe how they feel (Sabini, Garvey, and Hall 2001). Although data is preliminary, I argue that available evidence suggests that at least some psychopaths are capable of satisfying the subjectivity requirement for shame-based norms and therefore are open to shame-based forms of accountability.

I begin by briefly laying out relevant features of psychopathic agency. I pay special attention to two emerging subclasses of psychopaths in this analysis: successful psychopaths and secondary psychopaths. I then turn my attention to Russell's argument for the subjectivity requirement and his argument exempting psychopaths from responsibility. I conclude by claiming that even if we grant all of Russell's claims about psychopathic agency, they ought not fully exempt psychopaths, especially successful and secondary psychopaths, from shame-based forms of accountability.

\footnotetext{
${ }^{1}$ Greenspan's view is interesting because it allows for externalist routes to moral understanding and hence, although she believes that the subjectivity requirement might explain how most agents come to acquire moral understanding, she argues that the psychopath's failure of the subjectivity requirement should mitigate, to some degree, our judgment of the psychopath.
} 


\section{Psychopathy}

Psychopathy itself is a controversial construct (Skeem and Cooke 2010). A full specification of the condition is beyond the scope of this article; however, when I refer to psychopathy I mean to pick out the condition identified by Hervey Cleckley and elaborated upon by Robert Hare. This condition is most often diagnosed using a diagnostic tool called the Psychopathy Checklist (PCL-R). I do not intend to simultaneously refer to the condition known as Antisocial-Personality Disorder (ASPD) in the $5^{\text {th }}$ edition of the Diagnostic and Statistical Manual of Mental Disorders (American Psychiatric Association 2013).

There are important reasons for keeping these sometimes overlapping diagnoses distinct. For example, although about $80 \%$ of incarcerated men in the United States meet the diagnostic criteria for ASPD, only $15 \%-38 \%$ would meet the diagnostic criteria for psychopathy under the PCL-R standard (Hildebrand and deRuiter 2004). Psychopathy is a spectrum-disorder diagnosed primarily in terms of characteristic emotional profiles and personality traits. ${ }^{2}$ On the other hand, subjects may be diagnosed with ASPD based on a history of misconduct and law-breaking without regard to their personality traits or emotional capacities (Gurley 2009). Furthermore, I distinguish between what are known as 'primary' and 'secondary' forms of psychopathy. Primary psychopaths are sometimes defined in terms of their confidence and inflated perception of social rank along with high scores on self-esteem; secondary psychopaths perceive themselves as lower in social rank (especially in comparison with primary psychopaths) and demonstrate a propensity to engage in self-defeating behavior (Morrison and Gilbert 2001). This difference in perceptions of social rank and standing will factor in my assessment of the secondary psychopath's receptivity to shame. ${ }^{3}$

Perhaps the most notable diagnostic feature shared by psychopaths is a deficit of "empathic distress" or what is sometimes referred to as "mirroring" forms of empathy (Ramirez 2017b). Empathic distress is the name for the process by which neurotypical and autistic individuals come to instinctively find the pain of others aversive. Most individuals, if shown an image or film of others suffering, will tend to respond with characteristic behavioral and physiological changes correlated with distress (Fecteau, Pascual-Leone, and Theoret 2008; Ramirez 2017b). Psychopaths, on the other hand, tend to act with diminished, in some cases profoundly diminished, behavior associated with empathic distress. The degree to which individual psychopaths lack empathic distress can vary, which makes sense given its dimensional nature and the fact that these processes are not typically under conscious control (Decety 2012; Ly et al. 2012).

\footnotetext{
${ }^{2}$ Hervey Cleckley, who first operationalized the term "psychopath," identified sixteen traits ranging from "superficial charm" and "absence of remorse and shame" to "pathological egocentricity" and "untruthfulness and insincerity" to define the population (1941/1988, 338-399). Though Cleckley identifies some of these traits behaviorally (e.g., superficial charm), others are identified only via reference to internal mental states (e.g., absence of remorse or shame).

${ }^{3}$ Much disagreement exists about how best to understand the 'primary' and 'secondary' distinction. For example, while Morrison and Gilbert (2007) distinguish between primary and secondary psychopathy in terms of rank perception, some researchers argue that primary and secondary psychopaths should be distinguished in terms of whether they are capable of remorse and fear (Dean et al. 2012) or anxiety (Kimonis et al. 2011) while others focus on the differential standing of theorized Behavioral Inhibition Systems (BIS) and Behavioral Activation Systems (BAS) (Ross et al. 2007). Still others view primary psychopathy as congenital while secondary is acquired (Sethi et al. 2018).
} 
Psychopaths also notoriously have difficulty distinguishing between what psychologists refer to as moral norm violations and conventional norm violations (Dolan and Fullam 2010). They tend to behave as if all norms have the same kind of authority, namely they appear to behave as if all norms are norms of convention. Most of us note, for example, that there is a difference between wearing white after Labor Day and using someone's credit card without their permission. Although both are violations of a norm, subjects typically understand them as being importantly different.

Psychologists using the "moral/conventional" experimental paradigm have traditionally characterized moral norms as norms that are serious, harm-based, independent from authority, and that generalize beyond their present context. Norms of convention, on the other hand, are characterized as dependent on authority and whose scope is limited by context. For example, subjects generally believe that it would be wrong to steal from someone no matter the context whereas they are likely to relativize their judgment that it is wrong to wear white after Labor Day only to cultures that hold such a fashion norm. Children began to mark the moral/conventional distinction at a little over two years of age (Turiel 1977). Psychopaths, on the other hand, do not consistently or clearly behave as if there is a difference between these norms. Though the data regarding the "moral/conventional" experimental paradigm have been historically seen as important, they are not beyond challenge (Aharoni, Sinnott-Armstrong, and Kiehl 2012; Jalava and Griffiths 2017). The argument that follows is therefore predicated on results that may be overturned with refinements in experimental design and better data. ${ }^{4}$ In other words, if successful psychopathy survive as a genuine scientific category, the proceeding argument applies to its successful and secondary variants.

Historically, philosophers have interpreted psychopathic performance in the "moral/conventional" paradigm as a sign that psychopaths lack access to genuine moral concepts. ${ }^{5}$ Recently, there has been significant debate about the moral/conventional task and what it demonstrates about an individual's moral competence. Some critics claim that the characterization of morality assumed by psychologists in the moral/conventional task is incomplete. They argue that it does not capture an accurate

\footnotetext{
${ }^{4}$ It is difficult to say much with any precision when it comes to the study of psychopaths. In part this is because the term itself is under debate (Skeeme and Cooke 2010) though different researchers tend to use dramatically different populations which makes generalizing difficult. For example, Aharoni, Sinnott-Armstrong, and Kiehl (2014) used the PCL-R in their investigation of psychopathic understanding of the moral/conventional task. They drew their sample from a larger study of convicted felons which excluded those "age greater than 59, history of psychosis, loss of consciousness due to head injury greater than 15 minutes, English literacy below 4th grade level, intelligence quotient (IQ) less than 65" Aharoni, Sinnott-Armstrong, and Kiehl (2014, 5). They thus would not capture successful primary or secondary psychopaths in their study. Dolan and Fullam (2010) assessed juvenile psychopaths using the PCL-YV and claimed to have found differences between juvenile psychopaths and other incarcerated juveniles when it came to the moral/conventional distinction. In his pioneering study on the phenomenon, James Blair (1995) used PCL scores generated without interview and drawing exclusively from institutionalized populations.
}

5 Quite a few philosophers interpret the moral/conventional paradigm as demonstrating that psychopaths do not understand moral concepts at all. Neil Levy for example has argued that "psychopaths fail to grasp the distinction; for them, all transgressions are rule dependent" $(2007,131)$; Jesse Prinz has interpreted the moral/conventional data as showing "that psychopaths can give lip service to morality, but their comprehension is superficial at best" $(2007,44)$. Shaun Nichols has claimed that "although there is a sense in which psychopaths do know right from wrong, they don't know (conventional) wrong from (moral) wrong" and that this gives us "some justification in maintaining that they use moral terms only in an inverted-commas sense" $(2002,14)$. 
conception of morality (Vargas and Nichols 2007). Other critics, who have meta-ethical questions about the nature of morality and the value of the moral/conventional paradigm as a measure of moral knowledge, prefer to interpret psychopaths as capable of accessing moral concepts using non-emotional routes ignored by the task (Greenspan 2003; Kumar 2016; Maibom 2005, 2010b). I believe we can make progress by sidestepping these debates about the nature of moral concepts and moral knowledge. Even if critics of the standard interpretation of the moral/conventional paradigm are correct, the moral/conventional data do appear to capture a wide range of harm and fairness-based norms that psychopaths do not appear to understand in a neurotypical way. Furthermore, though meta-ethical questions about the nature of moral concepts can complicate what subjects may be doing when they perform the task, the divergences that appear in the task are worth taking seriously.

Psychopathy is also often comorbid with other personality disorders (Nioche et al. 2010; Warren et al. 2003). This can make it difficult to isolate the effects of psychopathy on individuals, as opposed to one or more of their comorbid conditions. There is evidence, however, that some psychopaths lack comorbid mental illnesses and are able to function relatively successfully in complicated social situations. These "successful psychopaths" are especially useful because they allow us to examine the effects of psychopathy in isolation from other conditions (Babiak et al. 2010). It remains a live possibility that successful psychopaths are capable of instrumental reasoning despite their other affective deficits (Jurjako and Malatesti 2016). Questions remain, however, regarding the nature of their capacity for distinctly moral reasoning (Ramirez 2013, forthcoming).

In what follows, I focus my analysis narrowly on successful psychopaths and on secondary psychopaths. Reactive theorists have tended to view the psychopath as exempt from moral responsibility in a general sense. I now examine the subjectivity requirement and the argument that it exempts psychopaths from responsibility.

\section{The subjectivity requirement}

Reactive theories of responsibility require that agents be able to feel reactive-attitudes and direct them at themselves to be the kind of agents that can be held responsible. Note that we can engage in self-protective measures against agents without holding them responsible. For example, we routinely cage or destroy dangerous animals while acknowledging that they are not responsible in a deep sense for the harms they cause. A dangerous animal may be causally responsible for harm or property damage while lacking the sort of agency that can make them morally responsible for what they do. If responsibility requires the capacity to direct reactive-attitudes at oneself then psychopaths, given their emotional deficits, might appear to be exempt from responsibility on this basis.

Responsible agents, on many theories, must have a certain kind of control over their actions that requires that the agent is rational in the right sort of way. ${ }^{6}$ This 'right way' involves having the capacity to direct reactive-attitudes at oneself. One reason to think that the capacity for self-directing emotions is important is because it might be essential that one be able to hold oneself accountable to be the sort of agent that can be held

\footnotetext{
${ }^{6}$ Wallace calls this kind of control "reflective self-control" (1994, 160-165) while Fischer and Ravizza have referred to it as "guidance control" $(1998,33)$. In both cases, control requires an affectively-informed capacity for reasons-responsiveness.
} 
accountable by others. That is, to be a candidate for praise or blame, one must be able to have the capacity to engage in praising and blaming practices and these practices are inextricably bound up with reactive-attitudes. An agent who did not feel or understand these emotions would therefore be incapable of understanding the practices of praise and blame that these emotions ground. "The responsible agent," Russell says, "must be able to feel and understand moral sentiments or reactive-attitudes" (Russell 2004, 295). Self-directed reactive-attitudes are important because they give us a kind of understanding of our moral practices. There is a sense in which access to these attitudes gives us access to the normative concepts involved in their application. Indeed, Russell goes so far as to say that " $[\mathrm{t}] \mathrm{o}$ appreciate and understand moral considerations fully is precisely to be able to apply them to oneself and others and feel the appropriate way when violations occur. Failing this the agent just 'does not really get it'” (Russell 2004, 295).

If we agree with Russell about the role of the subjectivity requirement, then we may be tempted to excuse psychopaths from responsibility because they seem to lack the capacity to direct the relevant attitude at themselves. Because they fail the subjectivity requirement, psychopaths 'do not really get it.' Their purported inability to feel the relevant attitudes leave them outside the moral community. This strand of thought is closely connected with another concerning the nature of moral reasons. If moral reasons are accessed (or constituted) by reactive-attitudes, then it makes sense that only agents that can feel reactive-attitudes can understand moral reasons in a way that would allow us to hold them accountable. These reasons are often taken as decisive reasons for excluding psychopaths from responsibility.

It is important to note that theories of responsibility are not simultaneously theories of punishment. A theory of responsibility tells us which agents are apt targets for punishment (i.e., which beings have the requisite capacities to be proper subjects of punishment in the first place) but it does not tell us when (if ever), or how much, to punish a person (Brink 2012). In saying that psychopaths can satisfy the subjectivity requirement and that they are therefore proper subjects of accountability, I claim that psychopaths can, on a reactive theory of responsibility, be proper subjects of punishment. They fit, in other words, within the general framework of our practice of holding one another accountable. I am not, however, claiming that we must punish them. Similarly, when philosophers like Neil Levy claim that psychopaths cannot satisfy the subjectivity requirement, they claim that psychopaths are not even the kind of beings who can come up for assessment within a theory of punishment (Levy 2007). They are exempt from these considerations.

Psychopaths, on that view, are more like dangerous animals than they are like other human agents (Levy 2007). If Levy is right, then psychopaths must be dealt with from the same perspective that we deal with other dangerous, but non-responsible, beings. We can see them as objects to control in the interest of public safety but it would be a mistake to treat them as if they were accountable for what they do (in the same way in which it would be a mistake to bring back the medieval practice of animal trials). If I am right, however, then psychopaths are at least apt candidates for punishment in much the same way neurotypical persons are. Other considerations, more properly belonging within the framework of a theory of punishment, would need to be addressed before we can say whether any psychopath should be subject to state-sanctioned punishment (Brink 2014). 


\section{Shame and the subjectivity requirement}

Although I will ultimately argue that at least some types of psychopaths have the sort of agency that allows us to hold them accountable, the pull of the subjectivity requirement is strong. There is something intuitively plausible about the claim that agents need some form of reactive understanding in order for it to be fair to hold them responsible. There does seem to be something unfair about holding someone responsible on the basis of emotions they cannot feel and thus cannot understand internally. This element of the subjectivity requirement is worth holding on to if possible.

In this section, I argue that at least some types of psychopaths can satisfy the subjectivity requirement with regard to shame. I intend these arguments to build on the claims from the previous section. Successful psychopaths, by most accounts, are able practical reasoners (Babiak, Neumann, and Hare 2010; Jurjako and Malatesti 2018; Ramirez 2015).7 If we feel the pull of the subjectivity requirement but are convinced, or are willing to grant for the sake of argument, that psychopaths are unable to feel or understand guilt, then we must look to attitudes other than guilt to ground psychopathic accountability.

To understand why psychopaths ought to be capable of feeling shame I need to explain what I mean by shame and how shame differs from embarrassment. Shame is a normatively powerful reactive-attitude. It can be directed both at the self (i.e., 'I should be ashamed of myself') but also onto others (i.e., 'they should be ashamed of themselves'). There is reason to think that many cultures use shame, instead of guilt, to govern many of their practices of praising and blaming (Benedict 1946/2006; Wong and Tsai 2007). Shame therefore seems like an ideal candidate for a reactive-attitude that can be used in place of guilt. It grounds a family of retributive practices that extend beyond guilt-based retributivism. If we want to make room for psychopathic responsibility and for the subjectivity requirement, then we can look to shame as a normatively powerful alternative to guilt.

Conflicting analyses of shame and embarrassment abound in the philosophical and psychological literatures (Calhoun, 2004; Deonna, Rodogno, and Teroni 2012; Keltner and Buswell 1997; Maibom 2010a; Ramirez 2017a; Tagney and Miller 1996; Taylor 1985; Williams 1986/2006). Shame and embarrassment, along with pride and guilt, are 'self-conscious emotions' because they function to keep track of assessments we and others make of our 'self.' Shame and embarrassment are similar to one another, and distinct from guilt, in the sense that they are sensitive to the ways that real or imagined others view us. Though similar, shame and embarrassment are also importantly different from one another.

Being outed as a liar seems like an occasion for shame whereas a verbal gaffe might be the subject of (mere) embarrassment. In both cases, each emotion is triggered by a scenario where an actual (or imagined) person judges one of our 'whole-self' properties. Whole-self properties are properties that relate to who we are as opposed to facts or judgments about what we have done. This connection with the self is an important marker that helps distinguish shame and embarrassment from other emotions. Guilt, for example, does not target the self but instead targets a person's actions. With guilt,

\footnotetext{
7 Though see Sifferd and Hirstein (2013) for both an alternative take on how to draw the successful/unsuccessful psychopathy distinction and the implications of such a distinction for moral responsibility.
} 
the focus is on something wrong that an agent has done. Within the logic of guilt, a person must focus on reparative action to undo the harm that the agent's own actions have caused. The kinds of judgments that ground shame and embarrassment, though they may sometimes relate to action, have a different focus. Although we feel guilty for what we have done, we are ashamed of ourselves. Actions matter with respect to shame only if they reveal an underlying negative aspect of the whole-self that an individual can feel ashamed about. Removing shame may involve reparative actions but the ultimate purpose of these actions is to become a different sort of person (a person who is no longer in possession of the relevant whole-self property that caused the shame in the first place).

I focus my analysis on one promising theory of shame and embarrassment developed by psychologist John Sabini and his colleagues (Sabini and Silver 1997; Sabini 2000; Sabini et al. 2001). Although I focus on one theory in particular, my argument is compatible with any theory of shame and embarrassment that rejects conceiving of these emotions as 'basic' or phylogenetically primitive. Although a full defense of this conception of emotion is beyond the scope of the article, there are independent reasons for thinking that emotions are best understood as non-basic psychological constructions (Barrett 2006; Lindquist et al. 2012; Roberson, van der Vyver, and Barrett 2014).

Sabini claims that shame and embarrassment are not distinct emotions. For example, Sabini argues that shame and embarrassment lack phenomenologically distinct feels. Instances of embarrassment can range from mild to severe as can instances of shame. Shame and embarrassment also appear to have the same reported objects (whole-self properties). Importantly, Sabini and his colleagues argue that shame and embarrassment lack emotion-specific physiological patterns that distinguish one from the other. Without a subject-independent way to distinguish embarrassment from shame, Sabini concludes that these emotions are best understood as resulting from the same affective process. This is what we should expect to discover if shame and embarrassment are not 'basic' emotional modules (Ramirez 2017a). On Sabini's view, shame and embarrassment are manifestations of the same emotion but the label that an agent attaches to that emotion (by calling it "shame" or "embarrassment") has an important social function. On their view, shame and embarrassment are behaviorally distinguishable from one another via a subject's choice of label. This label helps to communicate their attitudes about the situation that gave rise to it.

Both shame and embarrassment arise when we believe that others have appraised our whole-self properties (our character, talents, appearance, sexual identity, racial identity, etc.). We call our feeling shame, according to Sabini, when we wish to indicate (to ourselves or to others) that we agree, even if reluctantly, with the judgment that others (real or imagined) have made of us. ${ }^{8}$ We call the feeling embarrassment to express that we disagree with the evaluation made but that we agree that our (real or imagined) judges had rational grounds for their mistaken assessment. For example, if I find myself in a situation where I think I look like a slob but my sense of myself is that I'm not really all that slobby, then I will be embarrassed by the situation. I certainly look like a slob, but I am not really one (I don't perceive myself to manifest the whole-self property of 'being a slob'). On the other hand, Sabini claims that if we find ourselves in a situation where we believe that others do not even have grounds for their mistaken evaluation of our whole-self property then we will tend to respond with neither embarrassment nor shame but with anger (“I'm dressed perfectly well, you have no right to call me a slob!").

\footnotetext{
8 "Agreement" here does imply reflective endorsement of the norms that make the property a failing. For example, someone can feel ashamed of their heritage even if they would not reflectively endorse the norms that back this judgment (D'Arms and Jacobson 2003).
} 
We say that we are embarrassed when we accidentally spill food on ourselves because in doing so we express that we don't think we are clumsy even though it looks like we are. We say that we feel ashamed of ourselves if called a liar because, in doing so, we express that we believe we are a liar and the situation has exposed this fact about us. Note that we can have attitudes about ourselves that we would reject upon reflection or full information. According to Sabini:

When someone makes the appraisal that something has happened that might be taken as evidence that his or herself has been discredited, an emotional state is triggered. That painful, inhibiting state, one that leads one to want to become small and hide, might be called "State A." If the person is later asked (or for some other reason chooses) to describe that state, if the person wishes to imply that he or she sees the revealed flaw as real, then he or she will call it shame. However, if he or she wishes not to license the inference that he or she believes a real flaw of the self was revealed, then he or she will call it embarrassment. (Sabini, Garvey, and Hall 2001, 106)

On Sabini's view, anyone capable of feeling embarrassment should be capable of feeling shame. The two are both manifestations of State A. This fact about shame and embarrassment is crucial in determining whether psychopaths can satisfy the subjectivity requirement.

Readers convinced that embarrassment and shame are distinct in a robust sense are invited to consider whether the marker they believe serves to distinguish shame from embarrassment also requires revising other commonly accepted emotional subtypes. Psychologists often distinguish between "core," "animal-reminder" and "socio-moral" forms of disgust, for example (Haidt 1997). Each subtype of disgust is readily recognizable as an instance of the more general emotional category. This remains the case even though the three forms of disgust have different objects (food-based disease vectors, reminders of our animal natures, and immoral actions). They also have different constituent thoughts that accompany them.

Similarly, consider the stark differences between the experiences of "moral guilt" "survivor's guilt" and what is sometimes called "Catholic guilt." Although the relationship between the agent and wrongdoing is different in each case, all three are readily recognizable as instances of the more general emotional category: guilt. The connections between shame and embarrassment are at least as close, in this context, as the ones that exist between "core" and "socio-moral" forms of disgust or between "Catholic guilt" and "survivor's guilt." The fact that we lack a label for "State A" should, in this context, not serve as evidence against its existence given the lack of other independently distinguishing markers for shame and embarrassment.

There is, unfortunately, scant research into psychopathic susceptibility to shame and embarrassment. Though available data comprise only a handful of studies, they do suggest that psychopaths ought to be capable of feeling ashamed. If Sabini is right about the relationship between 'State $\mathrm{A}^{\prime}$ and embarrassment/shame then at least some psychopaths can satisfy the subjectivity requirement and can be held reactively accountable using shame-based attitudes and punishments.

To make headway on this question, it's instructive to look again at how some psychologists and philosophers have concluded that psychopaths do not understand moral concepts in the same way as non-psychopathic agents. In part, that conclusion was grounded on how psychopaths appeared to collapse moral norms into conventional norms. Although I remain agnostic about ongoing debates regarding the nature of 
'moral' presumed by the moral/conventional task, it is worth looking at the nature of the inference that the "moral/conventional" paradigm has been taken to license. Psychopathic judgments about norm violations diverged from non-psychopathic judgements of the same norms. Because psychopaths were seen as judging norm violations differently than neurotypical persons, it was inferred that they do not understand moral norms (in the same way as non-psychopaths).

Analogously, if psychopaths had a problem understanding embarrassment, we should expect their judgments about embarrassing scenarios to diverge from neurotypical judgments. There is some evidence that speaks directly to this question. Two studies, one focusing on psychopathic youth and the other on psychopathic adults, do not show this kind of divergence on psychopathic judgments about embarrassment (Blair 1995, 1997). They suggest that psychopathy does not undermine an agent's ability to understand embarrassment and therefore provide some evidence for psychopathic capacities for shame. Psychopathic susceptibility to shame and embarrassment is an understudied topic. ${ }^{9}$ The evidence that is available, however, speaks in favor of the possibility that some psychopaths are capable of feeling shame.

One study examined how psychopathic juveniles attributed emotions to characters in emotionally salient scenarios (Blair 1997). Subjects read each scenario and were then asked to say what emotion the character in the scenario should feel afterward. In line with those who interpret the "moral/conventional" paradigm as demonstrating an inability for psychopaths to understand moral concepts associated with guilt, psychopathic juveniles diverged dramatically from neurotypical juveniles on 'guiltscenarios' (scenarios where the character in the scenario is meant to feel guilty). They did not differ from neurotypical subjects in their attributions during happiness, fear, or embarrassment scenarios.

A second study used a similar methodology to examine the emotional attributions of adult psychopaths (Blair 1995). As in the previous study, adult psychopaths diverged from neurotypical agents only in scenarios where the character in the vignette is meant to feel guilty. As with juvenile psychopaths, adult psychopaths did not differ from controls in their attributions of happiness, sadness, or embarrassment to characters when the scenarios called for these emotions.

These results suggest that psychopaths understand embarrassment as well as any of us. Unlike data from the "moral/conventional" paradigm, psychopaths do not suffer from an embarrassment distinction failure. ${ }^{10}$ These results make sense if psychopaths feel what Sabini called 'State A.' Because the main worry stemming from the subjectivity requirement was a concern about the fairness of holding psychopaths accountable on the basis of reactive-attitudes they are not susceptible to, shame-based norms may be fairly applied to psychopaths. If embarrassment and shame are connected, then psychopaths satisfy the subjectivity requirement: they ought to have the capacity to feel ashamed of themselves. Additionally, secondary psychopaths (those who perceive themselves as lower in social rank and who can be occasionally impulsive and selfdestructive) have reported feelings shame (Campbell and Ellison 2005). Though data is tentative, and require replication, it is suggestive.

\footnotetext{
${ }^{9}$ James Blair has noted (personal communication, June 22, 2015) that research into this question is currently vanishingly small and that more research needs to be done in this area.

${ }^{10}$ Psychopaths will sometimes report feeling shame, though in varying degrees (and always to a lesser degree than non-psychopathic persons). Reports of shame appear to vary based on whether one is a "primary" or "secondary" psychopath (Morrison and Gilbert 2001).
} 
We now have the resources to show that at least some psychopaths satisfy the subjectivity requirement. Psychopaths ought to feel ashamed of themselves for treating people in ways that neglect the needs, concerns, or interests of others. This is because psychopaths have the capacity to feel ashamed about the kinds of people they are. The fact that many psychopaths elect not to be ashamed of themselves (because they do not wish to express that they agree with us about their whole-self failings) does not excuse them from accountability. In the case of successful and secondary psychopaths, we should presume the presence of a capacity to feel shame and therefore see them as open to shame-based forms of accountability.

Shame, unlike guilt, is not a distinctly moral attitude. Because guilt requires the judgment that one has acted wrongly, it necessarily requires the invocation of moral concepts in its application. The connection between guilt and morality is one reason why some have been tempted to view the psychopath's performance on the moral/conventional task, and Blair's vignette tasks, as evidence that psychopaths lack moral knowledge. If moral responsibility requires moral understanding and moral understanding is required to feel guilt, then this spells trouble for psychopathic responsibility. Shame, however, offers us another route for responsibility. Because shame does not require the tokening of moral concepts for its application (we can, are, and arguably ought to be ashamed of some of our amoral whole-self properties), it is possible to reach successful and secondary psychopaths via shame even if we believe that they are incapable of guilt.11

Shame can serve as a powerful ground for accountability. Shame-based retributive punishments, for example, are widespread and their use in many countries is increasing (Book 1999; Flanders 2006; Whitman 1998). When properly applied, shame has been found to be effective as a way of inhibiting recidivism when used in correctional contexts (Tangney, Stuewig, and Martinez 2014). It would be problematic to deploy retributive punishments against psychopaths if retributivism were a purely guilt-based practice. However, shame also grounds retributive practices. ${ }^{12}$ Since at least some psychopaths should be expected to understand reasons grounded in shame, then it would be fair to hold these psychopaths open to shame punishment even if we think they are also incapable of feeling guilt. Such psychopaths ought to be receptive to shame-based reasons and therefore ought to be open to shame-based punishment.

\section{A potential criticism}

It might be said that my account begs the question when it comes to psychopaths and shame and that it reveals a hidden problem with the subjectivity requirement itself. On the theory of shame and embarrassment I appeal to, shame and embarrassment are grounded on the same underlying affective mechanism. What differentiates shame from embarrassment depends on behavioral differences grounded in what the agents feeling the state are communicating to others about the assessments they perceive are being

\footnotetext{
11 Relevant non-moral whole-self properties here might include being: unprofessional, disgusting, rude, a bad artist, etc.

${ }^{12}$ Broadening the realm of normative accountability beyond the narrowly moral also helps us to avoid another problematic feature of reactive accounts. Dana Nelkin (2015) has argued, for example, that equating accountability with the conditions that make it appropriate to deploy moral reactive-attitudes may be a mistake.
} 
made of their whole-self properties. But, if Sabini and his colleagues are right then how do we make sense of data that suggests that psychopaths rarely self-report feeling ashamed of themselves and that these reports are typically provided by secondary psychopaths?

Psychopaths, an objector might say, though capable of embarrassment, are only capable of embarrassment because they can accept that others will perceive some aspect of their whole-selves as flawed but they are unable to see themselves in this way. This would imply that the psychopaths cannot feel ashamed of themselves. They cannot be ashamed because they lack another crucial capacity: the capacity to see that their character is flawed and to understand that it would be appropriate to feel ashamed given the kind of person they are. If psychopaths lack the capacity to see themselves as flawed or to understand that it would be appropriate to feel ashamed about their character, an objector might say, then that explains why they rarely claim to feel ashamed of themselves. It would be unfair, we might go on to say, to hold psychopaths accountable if they cannot see themselves as flawed in the way required by shame.

This is an interesting objection. What I wish to say is that even if this turns out to be the case, that this is a new and different assessment of the psychopath's normative failing. The subjectivity requirement identifies a lack of capacity for feeling as the source of the psychopath's normative confusion. This is not what is being said now. This objection goes beyond the subjectivity requirement in the sense that it requires that agents not only have the capacity to feel the relevant emotion but also to understand that they ought to see their characters as worthy of shame. In this case it is not a lack of capacity to feel shame that excuses. Instead, subjects' inability to see an aspect of their whole-self as flawed is what is meant to excuse them. Their inability to judge that it would be appropriate to feel ashamed of their character is now used as a means of excusing them from responsibility.

We should worry about a response like this. If I am right about how best to understand the nature of shame and embarrassment, then we should rightly wonder why the inability of psychopaths to be ashamed, as a result of this kind of incapacity, should excuse them from accountability given that they do not lack the capacity to feel ashamed. It matters, in other words, why psychopaths cannot understand that it would be appropriate to feel ashamed about the kind of characters they have cultivated. They may be responsible for this failing as well.

One feature that forms a major axis for a diagnosis of psychopathy, along with borderline personality disorder, is a narcissistic personality (Webster and Jonason 2013). If we must make sense of why it is that psychopaths appear to understand shame and embarrassment but do not readily (or often) report feeling ashamed of themselves, it may very well be that the narcissistic aspects of the psychopathic personality loom large in such an explanation.

Stated in this way, it is not obvious that psychopaths are failing the subjectivity requirement nor that they merit exemption from responsibility on the basis of their narcissistic traits. If narcissistic elements of a psychopathic personality explain why they are unable to see their character failings and this is meant to excuse them from responsibility, then these narcissistic personality traits should be exculpatory broadly (e.g., it should also excuse individuals with borderline or narcissistic personality disorders). However, powerful arguments have been raised to suggest that narcissism is better understood as a normative failing (to be corrected) than a mental illness (to be excused) (Charland 2004). 
A second problem is that this response threatens to exempt too many. If psychopaths are exempt from accountability because they cannot see themselves as flawed, then the danger is that any agents incapable of seeing themselves as flawed would also be exempt from accountability. The unrepentant slave-owner, the committed suicide bomber, and the staunch misogynist would join the psychopath as exempt from responsibility so long as each is convinced that what they are doing is right (Talbert 2012). This would require abandoning the intuitively plausible aspects of the subjectivity requirement that one needs to be able to feel the relevant reactive-attitudes in order to be held accountable. In all of these cases, the agents involved can feel guilt or shame (we might suppose), but their deeply held values prevent them from feeling it on specific occasions.

Instead, I suggest that reactive-attitude theorists rethink their relationship to the psychopath. Although psychopaths have profound affective irregularities these irregularities do not rise to a level that exempts them from all forms of accountability especially when we narrow our sights to successful psychopaths and secondary psychopaths. We need to take seriously the kind of will that these psychopaths can express and be ready to explore forms of accountability tied to shame appropriate to their capacities.

\section{Conclusion}

The Subjectivity Requirement is often thought to excuse psychopaths from accountability. I have argued that even if we grant that psychopaths are incapable of feeling guilty about what they do that at least two classes of psychopath-successful psychopaths and secondary psychopaths-are capable of feeling ashamed about the kinds of people they are. Psychopaths are open to shame even if they can rarely bring themselves, as a result of narcissistic personality traits, to accept this fact about themselves.

If I am right about the structure of shame and embarrassment, then psychopaths should be open not only to attitudes like resentment but also other normative attitudes like shame, disgust, hatred, and scorn. Because shame is not normative but not essentially moral, it would remain appropriate to hold psychopaths responsible using shame even if it turns out to be the case that psychopaths do not understand moral emotions like guilt. Although being open to shame-based punishment does not necessarily require that we punish, only a full theory of punishment can do this, we should consider punishment in the special case of psychopathy. In part this stems from the fact that standard therapeutic approaches fail to find much purchase with the psychopath. It is worth revisiting the forms of accountability that attitudes like shame can ground and especially important to broaden research on psychopathic receptivity to shame punishment.

\section{Acknowledgments}

I would like to thank Casey Hall, Dana Nelkin, Per Milam, James Blair, Marko Jurjako, and an anonymous reviewer for reading drafts of and giving comments on this article, all of which improved it beyond measure. 


\section{REFERENCES}

Aharoni, E., W. Sinnott-Armstrong, and K. A. Kiehl. 2012. Can psychopathic offenders discern moral wrongs? A new look at the moral/conventional distinction. Journal of Abnormal Psychology 121: 484-497.

Aharoni, E., W. Sinnott-Armstrong, and K. A. Kiehl. 2014. What's wrong? Moral understanding in psychopathic offenders. Journal of Research in Personality, 53, 175-181. http://doi.org/10.1016/j.jrp.2014.10.002

American Psychiatric Association. 2013. Diagnostic and Statistical Manual of Mental Disorders 5th ed. Washington, DC.

Babiak, P., C. Neumann, and R. Hare. 2010. Corporate psychopathy: Talking the walk. Behavioral Sciences and the Law 28: 174-193.

Barrett, L. F. 2006. Are emotions natural kinds? Perspectives on Psychological Science 1: 28-58.

Benedict, R. 1946/2006. The Chrysanthemum and the Sword: Patterns of Japanese Culture. Mariner Books.

Blair, R. J. R. 1995. A cognitive developmental approach to morality: investigating the psychopath. Cognition 57: 1-29.

Blair, R. J. R. 1997. Moral reasoning and the child with psychopathic tendencies. Personality and Individual Differences 22: 731-739.

Blair, R. J. R., C. Sellars, I. Strickland, F. Clark, A. O. Williams, M. Smith, and L. Jones. 1995. Emotional attributions in the psychopath. Personality and Individual Differences 19: 431-437.

Book, A. S. 1999. Shame on you: An analysis of modern shame punishment as an alternative to incarceration. William and Mary Law Review 40: 653-686.

Brink, D. 2012. Retributivism and legal moralism. Ratio Juris 25: 496-512.

Brink, D. 2014. Two kinds of culpability. San Diego Legal Studies Paper No. 14: 178.

Calhoun, C. 2004. An apology for moral shame. The Journal of Political Philosophy 12: 127-146.

Campbell J. S., and J. Elison. 2005. Shame coping styles and psychopathic personality traits. Journal of Personality Assessment 84: 96-104.

Charland, L. 2004. Character: Moral treatment and the personality disorders. In The Philosophy of Psychiatry, ed. J. Radden, 64-77. Oxford: Oxford University Press.

Churchland, P. M. (1981). Eliminative materialism and the propositional attitudes. Journal of Philosophy 78: 67-90.

Cleckley, H. 1941/1988. The Mask of Sanity: An Attempt to Clarify some Issues about the so-called Psychopathic Personality. 5th ed., scanned facsimile reproduced for nonprofit educational use. 
D'Arms J., and D. Jacobson. 2003. The significance of recalcitrant emotions: or antiquasijudgmentalism. In Philosophy and the Emotions, ed. A. Hatzimoysis, 127-145. Cambridge: Cambridge University Press.

Dean, A. C., L. L. Altstein, M. E. Berman, J. L. Constans, C. A. Sugar, and M. S. McCloskey. 2013. Secondary psychopathy, but not primary psychopathy, is associated with risky decision-making in noninstitutionalized young adults. Personality and Individual Differences, 54 (2): 272-277.

Decety, J., C. Chen, C. L. Harenski, and K. A. Kiehl. 2013. An fMRI study of affective perspective taking in individuals with psychopathy: Imagining another in pain does not evoke empathy. Frontiers in Human Neuroscience 7: 489.

Deonna, J., R. Rodogno, and F. Teroni. 2012. In Defense of Shame: The Faces of an Emotion. New York: Oxford University Press.

Dolan, M., and R. Fullam. 2010. Moral/conventional transgression distinction and psychopathy in conduct disordered adolescent offenders. Personality and Individual Differences 49: 995-1000.

Fecteau S., A. Pascual-Leone, and H. Theoret. 2008. Psychopathy and the mirror neuron system: Preliminary findings from a non-psychiatric sample. Psychiatry Research 160: 137-144.

Fine, C., and J. Kennett. 2004. Mental impairment, moral understanding and criminal responsibility: Psychopathy and the purposes of punishment. International Journal of Law and Psychiatry 121: 484-497.

Fischer, J. M., and M. Ravizza. 1998. Responsibility and Control: A Theory of Moral Responsibility. Cambridge: Cambridge University Press.

Flanders, C. 2006. Shame and the meanings of punishment. Cleveland State Law Review 54: 609-635.

Greenspan, P. S. 2003. Responsible psychopaths. Philosophical Psychology 16: 417-429.

Greenspan, P. S. 2016. Responsible psychopaths revisited. The Journal of Ethics, 20 (13): $265-278$.

Gurley, J. 2009. A history of changes to the criminal personality in the DSM. History of Psychology 12: 285-304.

Haidt, J. 1997. Body, psyche, and culture: The relationship between disgust and morality. Psychology \& Developing Societies 9: 107-131.

Hare, R., S. Hart, and T. Harpur. 1991. Psychopathy and the DSM-IV criteria for antisocial personality Disorder. Journal of Abnormal Psychology 100: 391-398.

Hildebrand, M., and C. deRuiter. 2004. PCL-R psychopathy and its relation to DSM-IV Axis I and Axis II disorders in a sample of male forensic psychiatric patients in the Netherlands. International Journal of Law and Psychiatry 27: 233-248.

Jalava, J., and S. Griffiths. 2017. Philosophers on psychopaths: A cautionary tale in interdisciplinarity. Philosophy, Psychiatry, \& Psychology 24: 1-12.

Jurjako, M., and L. Malatesti. 2016. Instrumental rationality in psychopathy: Implications from learning tasks. Philosophical Psychology 29: 717-731. 
Jurjako, M., and L. Malatesti. 2018. Psychopathy, executive functions, and neuropsychological data: A response to Sifferd and Hirstein. Neuroethics 11: 5565.

Keltner, D., and B. N. Buswell. 1997. Embarrassment: Its distinct form and appeasement functions. Psychological Bulletin 122: 250-270.

Kennett, J. 2010. Reasons, emotion, and the moral judgment in the psychopath. In Responsibility and Psychopathy, eds. L. Malatesti and J. McMillian, 243-259. Oxford: Oxford University Press.

Kimonis, E. R., J. L. Skeem, E. Cauffman, and J. Dmitrieva. 2011. Are secondary variants of juvenile psychopathy more reactively violent and less psychosocially mature than primary variants? Law and Human Behavior, 35 (5): 381-391.

Kumar, V. 2016. Psychopathy and internalism. Canadian Journal of Philosophy 46: 318345.

Levenson, M., K. Kiehl, and C. Fitzpatrick. 1995. Assessing psychopathic attributes in a noninstitutionalized population. Journal of Personality and Social Psychology 68: 151-158.

Levy, N. 2007. The responsibility of the psychopath revisited. Philosophy, Psychiatry, \& Psychology, 14: 129-138.

Lindquist, K. A., T. D. Wager, H. Kober, E. Bliss-Moreau, and L. F. Barrett. 2012. What are emotions and how are they created in the brain? Behavioral and Brain Sciences 35: 172-185.

Ly, M., J. C. Motzkin, C. L. Philippi, G. R. Kirk, J. P. Newman, K. A. Kiehl, and M. Koenigs. 2012. Cortical thinning in psychopathy. American Journal of Psychiatry 169: 743749.

Maibom, H. 2005. Moral unreason: The case of psychopathy. Mind and Language 20: 237-257.

Maibom, H. 2010a. The descent of shame. Philosophy and Phenomenological Research 80: 566-594.

Maibom, H. 2010b. Rationalism, emotivism, and the psychopath. In Responsibility and Psychopathy, eds. L. Malatesti and J. McMillian, 227-241. Oxford: Oxford University Press.

Morrison, D., and P. Gilbert. 2001. Social rank, shame and anger in primary and secondary psychopaths. The Journal of Forensic Psychiatry 12: 330-356.

Nelkin, D. 2015. Psychopaths, incorrigible racists, and the faces of responsibility. Ethics 125: 357-390.

Nichols, S. 2002. Sentimental Rules: On the Natural Foundations of Moral Judgment. Oxford: Oxford University Press.

Nioche, A., T. Pham, C. Ducro, C. de Beaurepaire, L. Chudzik, R. Courtois, and C. Réveillère. 2010. Psychopathy and associated personality disorders: Searching for a particular effect of the borderline personality disorder? Encephale 36: 253-259. 
Patrick, C. J. 2002. Aversive Pavlovian conditioning in the psychopaths: Peripheral and central correlates. Psychophysiology 39: 505-518.

Prinz, J. 2007. The Emotional Construction of Morals. Oxford: Oxford University Press.

Ramirez, E. 2013. Psychopathy, moral reasons, and responsibility. In Ethics and Neurodiversity, eds. A. Perry and C. Herrera, 217-237. Newcastle upon Tyne, Cambridge Scholars.

Ramirez, E. 2015. Receptivity, reactivity and the successful psychopath. Philosophical Explorations 18: 330-343

Ramirez, E. 2017a. A conditional defense of shame and shame punishment. Symposion 4: 77-95.

Ramirez, E. 2017b. Empathy and the limits of thought experiments. Metaphilosophy 48: 504-526.

Ramirez, E. forthcoming. Psychopathy, autism, and basic moral emotions: Evidence for sentimentalist constructivism. In The Bloomsbury Companion to the Philosophy of Psychiatry, eds. R. Bluhm and Ș. Tekin. New York: London: Bloomsbury

Ross, S. R., J. Molto, R. Poy, P. Segarra, M. Carmen Pastor, and S. Montañés. 2007. Gray's model and psychopathy: BIS but not BAS differentiates primary from secondary psychopathy in noninstitutionalized young adults. Personality and Individual Differences, 43 (7): 1644-1655.

Russell J., and L. F. Barrett. 1999. Core affect, prototypical emotional episodes, and other things called emotion: Dissecting the elephant. Journal of Personality and Social Psychology 76: 805-819.

Russell, P. 2004. Responsibility and the condition of the moral sense. Philosophical Topics 32 (1\&2): 287-306.

Sabini, J., B. Garvey, and A. Hall. 2001. Shame and embarrassment revisited. Personality and Social Psychology Bulletin 27: 104-117.

Sabini, J., and M. Silver. 1997. In defense of shame: Shame in the context of guilt and embarrassment. Journal for the Theory of Social Behavior 27: 1-15.

Sabini, J., M. Siepmann, J. Stein, and M. Meyerowitz. 2000. Who is embarrassed by what? Cognition and Emotion 14: 213-240.

Sethia, A., E. McCrory, V. Puetz, F. Hoffmann, A. R. Knodt, S. R. Radtke, B. D. Brigidi, A. R. Hariri, and E. Vidinga. 2018. Primary and secondary variants of psychopathy in a volunteer sample are associated with different neurocognitive mechanisms. Biological Psychiatry: Cognitive Neuroscience and Neuroimaging. https://doi.org/10.1016/j.bpsc.2018.04.002

Sifferd, K., and W. Hirstein. 2013. On the criminal culpability of successful and unsuccessful psychopaths. Neuroethics 6: 129-140.

Smith, A. M. 2012. Attributability, answerability, and accountability: In defense of a unified account. Ethics 122: 575-589. 
Skeeme, J. L., and D. J. Cooke. 2010. Is criminal behavior a central component of psychopathy? Conceptual directions for resolving the debate. Psychological Assessment 22: 433-445.

Strawson, P. F. 1962. Freedom and resentment. Proceedings of the British Academy 48: $1-25$.

Tangney, J., and R. Miller. 1996. Are shame, guilt, and embarrassment distinct emotions? Journal of Personality \& Social Psychology 70: 1256-1269.

Tangney J., J. Stuewig, and A. G. Martinez. 2014. Two faces of shame: The roles of shame and guilt in predicting recidivism. Psychological Science 25: 799-805.

Talbert, M. 2012. Moral competence, moral blame, and protest. Journal of Ethics 16: 89109.

Taylor, G. 1985. Pride, shame, and guilt: Emotions of self-assessment. Oxford: Oxford University Press.

Turiel, E. 1977. Distinct conceptual and developmental domains: Social convention and morality. Nebraska Symposium on Motivation 25: 77-116.

Vargas, M., and S. Nichols. 2007. Psychopaths and moral knowledge. Philosophy, Psychiatry, \& Psychology 14: 157-162.

Wallace, J. 1994. Responsibility and the Moral Sentiments. Cambridge, Mass: Harvard University Press.

Warren J. I., M. L. Burnette, S. C. South, P. Chauhan, R. Bale, R. Friend, and I. Van Patten. 2003. Psychopathy in women: Structural modeling and comorbidity. International Journal of Law and Psychiatry 26: 223-242.

Webster, G. D., and P. K. Jonason. 2013. Putting the "IRT" in "Dirty": Item response theory analyses of the dark triad dirty dozen-An efficient measure of narcissism, psychopathy, and Machiavellianism. Personality and Individual Differences 54: 302-306.

Whitman, J. 1998. What is wrong with inflicting shame sanctions? The Yale Law Journal 107: 1055-1092.

Williams, B. 1989/2006. Shame and Necessity. Berkeley and Los Angeles: University of California Press.

Wong, Y., and J. Tsai. 2007. Cultural models of shame and guilt. In The Handbook of SelfConscious Emotions, eds. J. Tracy, R. Robins, and J. Tangney, 210-223. New York, NY: Guilford. 